\title{
Travel-related illness at a tertiary care hospital in Osaka, Japan
}

This article was published in the following Dove Press journal:

International Journal of General Medicine

20 October 2016

Number of times this article has been viewed

\section{Yoshiro Hadano \\ Michinori Shirano \\ Tetsushi Goto \\ Center for Infectious Diseases, Osaka \\ City General Hospital, Osaka, Japan}

\begin{abstract}
We analyzed the travel-related health problems in persons returning to Japan from overseas. Data were extracted retrospectively for all patients visiting the infectious diseases department of Osaka City General Hospital, Osaka, Japan, between July 2012 and September 2013. There were 209 sick returning travelers during the period of the study. The median age of the subjects was 34.3 years, and the subjects consisted of 133 tourists (63.6\%), 39 business travelers (18.7\%), 17 expatriates $(8.1 \%), 14$ volunteer workers $(6.7 \%)$, and four persons who visited friends and relatives (1.9\%). The most visited destinations were Asia $(n=162,77.5 \%)$, including East Asia $(n=26,12.4 \%)$, Southeast Asia $(n=116,55.5 \%)$, South Asia $(n=25,12.0 \%)$, Central Asia ( $n=3,1.4 \%)$, and Africa $(n=30,14.3 \%)$. The most commonly diagnosed diseases were gastrointestinal tract infection $(n=81,38.8 \%)$, dengue fever $(n=26,12.4 \%)$, and animal bites $(n=26,12.4 \%)$. Twenty-nine patients $(13.8 \%)$ were hospitalized, mainly for dengue fever and gastrointestinal tract infection.
\end{abstract}

Keywords: travel medicine, travel-related health problems, Japan

\section{Introduction}

With the expansion of the commercial air traffic network, international travel has become commonplace. In 2014, the number of international tourist arrivals all over the world was estimated at 1 billion, up from the estimated 1,087 million in $2013 .{ }^{1}$ Japanese citizens are also increasingly traveling overseas. According to the Japan Association of Travel Agents, the number of Japanese traveling abroad was approximately 18.4 million in 2013, trending toward an increase as compared to the estimated number of 17.3 million in $2007 .^{2}$ In 2009 , a report was published describing travelrelated health problems in travelers returning to Tokyo, Japan. ${ }^{3}$ However, no such data exist for the Kansai region, including Osaka. In this descriptive study, we report the results of our analysis of the travel-related health problems in travelers returning from overseas to Osaka, Japan.

\section{Materials and methods}

The study was a single-center, retrospective descriptive study. We included all adult (>15 years) travelers returning to their country of residence from overseas, who were diagnosed as having one or more travel-related diseases. We extracted the records of all the patients visiting the Center for Infectious Diseases at Osaka City General Hospital (OCGH), a 1,063-bed tertiary care hospital in Osaka, Japan, between July 1, 2012 and September 30,2013 . OCGH is in charge of pre-travel health-related consultation and post-travel
Conce: Yoshiro Hadano

City General Hospital, 2-13-22,

Miyakojima-hondori, Miyakojima-ku,

Osaka, 5344-002I, Japan

Tel +8166929 I22I

Fax +8I 669290623

Email hatayoshiyoshi@yahoo.co.jp 
health problems in travelers. The following demographic data of the study participants were analyzed: age, sex, nationality, category of travel (tourism, business, expatriates, volunteer work, and visiting friends/relatives), travel destinations, including the geographical region (East Asia, Southeast Asia, South Asia, Central Asia, Africa, Oceania, North America, South America, and Europe), chief health-related complaints at the first consultation, primary diagnosis, and hospitalization status. If the overseas destinations had included more than two countries, all visited countries were included in the data. This study was approved by the Osaka City General Hospital Ethics Committee. As a retrospective study, only medical records were reviewed. No patient was directly involved in the study. As a result, the Osaka City General Hospital Ethics Committee waived the requirement for patient consent.

\section{Results}

There were 209 sick returning travelers during the 15-month study period, consisting of 85 men (40.7\%) and 124 women $(59.3 \%)$. The median age was 32 years $(15-78$ years). Depending on the category of travel, the subjects were classified into 133 tourists $(63.6 \%), 39$ business travelers $(18.7 \%), 17$ expatriates $(8.1 \%), 14$ volunteer workers $(6.7 \%)$, and four travelers who had visited friends and relatives $(1.9 \%)$. The median interval between return to the country of residence and visit to our hospital was 7.3 days (1-120 days) and the median time from onset of symptoms to visiting our clinic was 6.7 days (1-90 days). Of the 209 persons, 140 (66.9\%) visited our hospital directly, 69 (33.1\%) were referred to our hospital from another clinic or hospital (55 patients, 26.4\%), or from a quarantine station (14 patients, 6.7\%). The travel destinations were distributed as follows: Asia ( $n=162,77.5 \%)$, including East Asia ( $n=26,12.4 \%)$, Southeast Asia $(n=116,55.5 \%)$, South Asia $(n=25,12.0 \%)$, Central Asia $(n=3,1.4 \%)$, Africa $(n=30$, $14.3 \%)$, Oceania ( $n=3,1.43 \%)$, North America $(n=7,3.3 \%)$, South America $(n=4,1.9 \%)$, and Europe $(n=3,1.43 \%)$ (Table 1$)$. The destinations included 48 countries around the world, with the top five being Thailand ( $n=31)$, Indonesia ( $n=27$ ), including Bali island $(n=17)$ and other regions $(n=10)$, People's Republic of China ( $n=17)$, Cambodia $(n=13)$, and Malaysia $(n=7)$.

Among the 209 patients, the most frequent presenting complaints were as follows: fever $(n=110,52.6 \%)$, diarrhea $(n=48,23.0 \%)$, and animal bites $(n=26,12.4 \%)$ (Table 2$)$. The primary diagnoses are shown in Table 3 . The most common diagnoses were gastrointestinal tract infection $(n=81$, $38.8 \%)$, dengue fever $(\mathrm{n}=26,12.4 \%)$, and animal bites $(\mathrm{n}=26,12.4 \%)$. Among the patients diagnosed as having gastrointestinal infection, stool examination was performed in 68 patients, and causative pathogens were identified in 19 patients (six Plesiomonas spp., three Shigella spp., three Salmonella spp., two Aeromonas spp., one Campylobacter jejuni, one Clostridium perfringens, one Bacillus cereus,

Table I Reported diagnosis according to the area of travel in travelers returning to Japan

\begin{tabular}{|c|c|c|c|c|c|c|c|c|c|c|}
\hline Primary diagnosis & $\begin{array}{l}\text { Number } \\
\text { of } \\
\text { patients }\end{array}$ & $\begin{array}{l}\text { East Asia } \\
N=26\end{array}$ & $\begin{array}{l}\text { Southeast } \\
\text { Asia } \\
\mathbf{N}=1 \text { I } 6\end{array}$ & $\begin{array}{l}\text { South } \\
\text { Asia } N=25\end{array}$ & $\begin{array}{l}\text { Central } \\
\text { Asia } \\
\mathbf{N}=3\end{array}$ & $\begin{array}{l}\text { Africa } \\
\mathbf{N}=30\end{array}$ & $\begin{array}{l}\text { Oceania } \\
N=3\end{array}$ & $\begin{array}{l}\text { North } \\
\text { America } \\
\mathbf{N}=7\end{array}$ & $\begin{array}{l}\text { South } \\
\text { America } \\
N=4\end{array}$ & $\begin{array}{l}\text { Europe } \\
\mathbf{N}=3\end{array}$ \\
\hline Gastrointestinal infections & 81 & 13 & 42 & 8 & 2 & 8 & 2 & 4 & I & 0 \\
\hline Dengue fever & 26 & 0 & 24 & 2 & 0 & 0 & 0 & 0 & 0 & 0 \\
\hline Animal bites & 26 & 4 & 10 & 10 & I & I & 0 & 0 & 0 & 0 \\
\hline Acute respiratory infections & 23 & 2 & 11 & 2 & 0 & 4 & I & 2 & I & 0 \\
\hline Influenza & 7 & I & 4 & 0 & 0 & 2 & 0 & 0 & 0 & 0 \\
\hline Pneumonia & 4 & 0 & 2 & I & 0 & 0 & 0 & 0 & 0 & I \\
\hline Skin problems & 3 & 0 & I & 0 & 0 & 0 & 0 & I & 0 & I \\
\hline Malaria falciparum & 3 & 0 & 0 & 0 & 0 & 3 & 0 & 0 & 0 & 0 \\
\hline Typhoid and paratyphoid fever & 2 & 0 & 0 & 0 & 0 & 0 & 0 & 0 & 2 & 0 \\
\hline Infectious mononucleosis & 2 & 0 & 2 & 0 & 0 & 0 & 0 & 0 & 0 & 0 \\
\hline Streptococcal infections & 2 & 0 & 2 & 0 & 0 & 0 & 0 & 0 & 0 & 0 \\
\hline Rubella & 2 & I & 1 & 0 & 0 & 0 & 0 & 0 & 0 & 0 \\
\hline Hepatitis A & 2 & 0 & 2 & 0 & 0 & 0 & 0 & 0 & 0 & 0 \\
\hline Measles & I & 0 & I & 0 & 0 & 0 & 0 & 0 & 0 & 0 \\
\hline Urinary tract infection & I & 0 & 0 & 0 & 0 & 0 & 0 & 0 & 0 & I \\
\hline Chikungunya fever & I & 0 & I & 0 & 0 & 0 & 0 & 0 & 0 & 0 \\
\hline Tuberculosis & I & 1 & 0 & 0 & 0 & 0 & 0 & 0 & 0 & 0 \\
\hline Acute appendicitis & I & I & 0 & 0 & 0 & 0 & 0 & 0 & 0 & 0 \\
\hline Diverticulitis & I & 0 & I & 0 & 0 & 0 & 0 & 0 & 0 & 0 \\
\hline Duodenal cancer & I & 0 & I & 0 & 0 & 0 & 0 & 0 & 0 & 0 \\
\hline Unknown & 19 & I & 9 & 2 & 0 & 7 & 0 & 0 & 0 & 0 \\
\hline Total & 209 & 26 & 116 & 25 & 3 & 30 & 3 & 7 & 4 & 3 \\
\hline
\end{tabular}


Table 2 Chief complaints in travelers returning to Japan

\begin{tabular}{ll}
\hline Chief complaint & Number of patients \\
\hline Fever & $110(52.6 \%)$ \\
Diarrhea & $48(23.0 \%)$ \\
Animal bites & $26(12.4 \%)$ \\
Medical check-up & $5(2.4 \%)$ \\
Upper respiratory symptoms & $5(2.4 \%)$ \\
General fatigue & $4(1.9 \%)$ \\
Abdominal pain & $4(1.9 \%)$ \\
Jaundice & $2(1.0 \%)$ \\
Other symptoms & $5(2.4 \%)$ \\
Total & $209(100 \%)$ \\
\hline
\end{tabular}

Table 3 Primary diagnosis in 209 patients who were travelers returning to Japan

\begin{tabular}{ll}
\hline Diseases & Number of patients \\
\hline Gastrointestinal tract infections & 81 \\
Dengue fever & 26 \\
Animal bites & 26 \\
Acute respiratory tract infections & 23 \\
Influenza & 7 \\
Pneumonia & 4 \\
Skin problems & 3 \\
Malaria & 3 \\
Typhoid and paratyphoid fever & 2 \\
Infectious mononucleosis & 2 \\
Streptococcal infections & 2 \\
Rubella & 2 \\
Hepatitis A & 2 \\
Measles & 1 \\
Urinary tract infection & 1 \\
Chikungunya fever & $\mathrm{I}$ \\
Tuberculosis & $\mathrm{I}$ \\
Acute appendicitis & $\mathrm{I}$ \\
Diverticulitis & $\mathrm{I}$ \\
Duodenal cancer & $\mathrm{I}$ \\
Unknown & 19 \\
Total & 209 \\
\hline
\end{tabular}

one Staphylococcus aureus, and one Entamoeba histolytica). Among the 110 patients presenting with fever, the primary diagnoses were as follows: gastrointestinal tract infection $(n=28,25.5 \%)$, dengue fever $(n=26,23.6 \%)$, acute respiratory tract infections $(n=20,18.2 \%)$, influenza $(n=7,6.4 \%)$ and pneumonia $(n=4,3.6 \%)$, malaria $(n=3,2.7 \%)$, including Plasmodium falciparum (three patients), typhoid fever $(\mathrm{n}=2$, $1.8 \%)$, infectious mononucleosis $(n=2,1.8 \%)$, streptococcal infections $(n=2,1.8 \%)$, rubella $(n=2,1.8 \%)$, measles $(n=1$, $0.9 \%)$, chikungunya fever $(n=1,0.9 \%)$, and diverticulitis $(n=1,0.9 \%)$. The cause of the fever remained unknown in nine patients $(8.1 \%)$ (Table 4$)$. Among the patients diagnosed as having dengue fever, there were no cases of severe illness. In all, 29 patients (13.8\%) were hospitalized, and
Table 4 Diseases diagnosed in II0 febrile patients who were travelers returning to Japan

\begin{tabular}{ll}
\hline Diagnosis & Number of patients \\
\hline Gastrointestinal tract infections & $28(25.5 \%)$ \\
Dengue fever & $26(23.6 \%)$ \\
Acute respiratory tract infections and & $20(18.2 \%)$ \\
influenza-like illness & \\
Influenza & $7(6.4 \%)$ \\
Pneumonia & $4(3.6 \%)$ \\
Malaria & $3(2.7 \%)$ \\
Typhoid and paratyphoid fever & $2(1.8 \%)$ \\
Infectious mononucleosis & $2(1.8 \%)$ \\
Streptococcal infections & $2(1.8 \%)$ \\
Rubella & $2(1.8 \%)$ \\
Measles & $\mathrm{I}(0.9 \%)$ \\
Hepatitis A & $\mathrm{I}(0.9 \%)$ \\
Measles & $\mathrm{I}(0.9 \%)$ \\
Chikungunya fever & $\mathrm{I}(0.9 \%)$ \\
Diverticulitis & $\mathrm{I}(0.9 \%)$ \\
Unknown & $9(8.1 \%)$ \\
Total & $\mathrm{I} 10(100 \%)$ \\
\hline
\end{tabular}

Table 5 Diseases diagnosed in 29 hospitalized patients who were travelers returning to Japan

\begin{tabular}{ll}
\hline Diseases & Number of patients \\
\hline Dengue fever & $8(27.6 \%)$ \\
Gastrointestinal tract infections & $7(24.1 \%)$ \\
Pneumonia & $4(13.8 \%)$ \\
Typhoid and paratyphoid fever & $2(6.9 \%)$ \\
Malaria & $2(6.9 \%)$ \\
Streptococcal infections & $\mathrm{I}(3.4 \%)$ \\
Acute appendicitis & $\mathrm{I}(3.4 \%)$ \\
Hepatitis A & $\mathrm{I}(3.4 \%)$ \\
Duodenal cancer & $\mathrm{I}(3.4 \%)$ \\
Measles & $\mathrm{I}(3.4 \%)$ \\
Rubella & $\mathrm{I}(3.4 \%)$ \\
Total & $29(100 \%)$ \\
\hline
\end{tabular}

190 patients were treated on an outpatient basis. The main reasons for admission were dengue fever and gastrointestinal tract infection (Table 5). In regard to the travel destination, $23(79.3 \%)$ patients had been to Asia, four (13.8\%) to Africa, and one each (3.4\%) to North America and South America, respectively. All of the hospitalized patients improved.

\section{Discussion}

To the best of our knowledge, this is the second study of travel-related health problems in returning travelers to Japan, carried out at the OCGH, Osaka. In this study, $77.5 \%$ of the patients were returning after having traveled to other countries in Asia, especially Southeast Asia. This suggests a difference in the destinations of travel from persons in Western countries. ${ }^{4,5}$ In similar studies reported from Western countries, up to $50 \%$ of returning travelers with travel-related 
health problems had been to Africa. Therefore, the distribution of travel-related medical problems in returning travelers in Japan was different. It is important for physicians in Japan to be aware of the tendency of travelers returning from travel to other Asian countries, especially in Southeast Asia, to show post-travel health problems.

There were only three cases of malaria during the study period, and all were returning after travel to Africa. There are two possible reasons for this. First, there were only four "visiting friends/relatives" travelers and Africa was not the destination for any. In general, immigrants who visit friends and relatives are at an increased risk of infections associated with their travel. Second, the percentage of travelers returning from Africa, where malaria is endemic, was only $14.3 \%$, as compared to $30 \%$ in the previous study carried out in Tokyo, Japan. ${ }^{3}$ According to the imported malaria surveillance in Japan, $76 \%$ of cases are travelers who had contracted the disease in Africa. ${ }^{6}$ Although malaria is a rare disease in Japan, physicians should not rule it out.

By contrast, imported dengue fever is increasing year by year in Japan. In this study, $23.4 \%$ of the patients who presented with fever were diagnosed as having dengue fever and almost all patients were returning after travel to Southeast Asia. The estimated number of imported dengue fever cases in Japan was 244 in 2010 as compared to 74 in $2005 .^{7}$ Moreover, a case of dengue fever without a patient history of traveling to foreign countries was confirmed in Japan, after a dengue outbreak occurred in Tokyo, Japan, in $2014 .{ }^{8}$ Thus, dengue fever is becoming one of the more commonly encountered traveler's diseases in Japan, especially in travelers returning from Southeast Asia.

Among the 209 subjects of this study, the most frequent presenting complaint was fever, and the primary diagnoses included non-tropical diseases such as infectious mononucleosis, streptococcal infections, and diverticulitis. In addition, acute appendicitis and duodenal cancer were diagnosed in the patients presenting with fever. It is important for the physician to keep in mind both tropical diseases and non-tropical diseases in the differential diagnosis. In this study, $13.8 \%$ of the patients were hospitalized and the main reasons for hospitalization were dengue fever, gastrointestinal tract infection, and pneumonia. This trend is similar to that observed in previous studies, after exclusion of the patients with malaria. ${ }^{9,10}$
There are some limitations to this study. To begin with, the data were extracted from the records of a single center, and the results of the study are representative just for the population which relates to this hospital. Another limitation was that not all patients were returning travelers because $26 \%$ were referred from another clinic or hospital, and self-limiting diseases may be underrepresented. Finally, our hospital is not a Geo Sentinel site.

\section{Conclusion}

Nevertheless, our study describes the epidemiology of travel-related health problems among returning travelers to Osaka, Japan. Gastrointestinal tract infection, dengue fever, and animal bites were the most common diseases affecting the returned traveler. These data may be useful for doctors in Japan of pre- and post-travel consultations, especially in Osaka. Physicians in Japan have to learn the epidemiology and common tropical diseases in Southeast Asia.

\section{Disclosure}

The authors report no conflicts of interest in this work.

\section{References}

1. World Tourism Organization UNWTO [homepage on the Internet]. UNWTO Annual Report 2014. Madrid: World Tourism Organization; 2015. Available from: http://www2.unwto.org/annualreport2014. Accessed August 19, 2016.

2. Japan Association of Travel Agents [homepage on the Internet]. Ryokou Tokei 2014. Tokyo: Japan Association of Travel Agents Online Resources, ${ }^{\circ} \mathrm{JATA}$. Available from: http://www.jata-net.or.jp/. Accessed August 19, 2016. Japanese.

3. Mizuno Y, Kudo K. Travel-related health problems in Japanese travelers. Travel Med Infect Dis. 2009;7(5):296-300.

4. Ansart S, Perez L, Vergely O, Danis M, Bricaire F, Caumes E. Illnesses in travelers returning from the tropics: a prospective study of 622 patients. J Travel Med. 2005;12(6):312-318.

5. Doherty JF, Grant AD, Bryceson AD. Fever as the presenting complaint of travellers returning from the tropics. QJM. 1995;88(4):277-281.

6. Mizuno Y, Kato Y, Kano S, Takasaki T. Imported malaria and dengue fever in returned travelers in Japan from 2005 to 2010. Travel Med Infect Dis. 2012;10(2):86-91.

7. National Institute of Infectious Diseases [homepage on the Internet]. Annual surveillance data table Tokyo: National Institute of Infectious Disease, 1998. National Institute of Infectious Diseases, Japan. Available from: http://www.nih.go.jp/niid/ja/from-idsc.html. Accessed August 19, 2016. Japanese.

8. Kutsuna S, Kato Y, Moi ML, et al. Autochthonous dengue fever, Tokyo, Japan, 2014. Emerg Infect Dis. 2015;21(3):517-520.

9. Stienlauf S, Segal G, Sidi Y, Schwartz E. Epidemiology of travel-related hospitalization. J Travel Med. 2005;12(3):136-141.

10. O'Brien D, Tobin S, Brown GV, Torresi J. Fever in returned travelers: review of hospital admissions for a 3-year period. Clin Infect Dis. 2001;33(5):603-609. 
The International Journal of General Medicine is an international, peer-reviewed open-access journal that focuses on general and internal medicine, pathogenesis, epidemiology, diagnosis, monitoring and treatment protocols. The journal is characterized by the rapid reporting of reviews, original research and clinical studies across all disease areas.
The manuscript management system is completely online and includes a very quick and fair peer-review system, which is all easy to use. Visit http://www.dovepress.com/testimonials.php to read real quotes from published authors. 